\title{
Speaking truth to power: Mental health service users' experiences of participation in their diagnosis and treatment
}

\author{
Gloria Kirwan ${ }^{1}$
}

\begin{abstract}
In a qualitative study, long-term mental health service users shared their views on the concept of 'participation' as shaped by their personal histories of contact with mental health services in Ireland. Adopting a narrative methodology, the study participants were asked to draw on their experiences with mental health services to illustrate their general views on participation by service users in mental health care contexts. In this study, the research participants recounted positive experiences of participation in which their expressed views regarding their symptoms and treatment needs were incorporated into the service responses they received. The data revealed that service users perceived open and inclusive communication by service providers as an important factor in optimising their ability to participate in help-seeking, diagnosis and treatment plans. However, the study also illuminated the chilling effect on participation when service users' views were not heeded or acknowledged by service providers. The findings highlight how the failure to include service users' insights can negatively encroach on service user participation. The service user narratives collected in this study exposed the often uneasy juxtaposition of the service user's personally held 'truth' regarding their lived experience of mental distress versus the powerful system of expert diagnosis and treatment. This article focuses on reporting selective findings from the study regarding participation in the contexts of help-seeking, diagnosis and treatment decisions.
\end{abstract}

\section{Keywords:}

1. Department of Applied Social Studies, Maynooth University, Ireland

Address for correspondence: Gloria.Kirwan@mu.ie

Date of first (online) publication: 15th September 2020 


\section{Introduction}

This article reports on selected findings from a small-scale study (Kirwan, 2017) in which long-term mental health service users in Ireland were asked to articulate their vision of optimum service user participation in the processes of mental illness diagnosis and treatment. Specifically, the study participants were asked to narrate their views on participation with reference to their personal experiences of mental health service usage. The analysis revealed that the study participants welcomed opportunities for participation in processes of help-seeking, diagnosis and treatment but were dissatisfied with situations in which the insights they provided (or could have provided) into their mental health-related needs were not incorporated into the service responses they received.

\section{Background}

The World Health Organisation (WHO, 2019) reports that the incidence of mental illness (as part of a wider spectrum of mental disorders) is rising across the world. In the European context, the prevalence of mental disorders, including mental illness, is described by the World Health Organisation's Regional Office for Europe (2019) as 'one of the most significant health challenges' facing the European region. The World Health Organisation (WHO, 2013) has also highlighted the human rights dimension of mental health care, pointing to the importance of addressing issues such as stigma, prejudice and social exclusion in the effort to ameliorate the impact on individuals of a mental illness diagnosis. This rights-based focus has fostered interest in making provision for the active engagement by mental health service users in their contacts with mental health services. In this evolving context, participation by mental health service users is garnering increasing support in policy, service delivery and service user discourses.

Discernible support for participation within the Irish mental health policy agenda tallies with this wider, international policy push for mental health service user participation in mental health care. Current Irish mental health policy, as articulated in A Vision for Change (DoH, 2006) and Sharing the Vision (DoH, 2020), with their promise of participation, partnership and service-user informed service development, essentially presents a blended citizenship/consumerist agenda for mental health service user participation in Ireland. Despite this expressed emphasis on service user participation in Irish mental health policy, the issue of participation by mental health service users has been generally unproblematised with little research attention directed towards establishing what service users themselves view as optimum service user participation.

It is within this participation-oriented but evidence-light context that the present 
study set out to ascertain how the phenomenon of participation is experienced by mental health service users in their contact with mainstream Irish mental health services. The decision to focus on the views of service users in this study was influenced by Croft $\&$ Beresford's (1992, p. 27) call for the study of participation in mental health contexts to be conducted with reference to 'existing knowledge and experience'. This study aimed to conduct research with a sample of participants whose knowledge of participation was informed by their experiences of contact with mental health services over a period of years, or, in some cases, decades. The research design focused on collecting the views of this population of service users regarding their knowledge of participation at the individual level of mental health service usage. The study aimed to ascertain service users' views on optimum participation and the factors which they believed had either supported or inhibited optimum participation by them in their contact with mental health services during their lived experiences of help-seeking, diagnosis and treatment.

\section{The concept of participation}

According to Beresford (2012, p.21), the problem with the term 'participation' and its close relative 'service-user involvement', is that it is 'routinely used to include as diverse a range of activities as volunteering, campaigning, pressure group politics, consultation, satisfaction surveys and lobbying'. It is useful, therefore, to look more closely at the meanings or interpretations of participation in the specific contexts of health and mental health service delivery.

In the wider healthcare sphere, Stiggelbout, Pieterse \& De Haes (2015) reference Veatch (1972) as one of the first writers to identify what he termed 'shared decisionmaking' with patients (here referred to as service users ) in his paper on models for ethical medical practice. Despite this linkage of participation with ethical practice, Stigglebout et al (2015) point out that the concept of participation in the context of healthcare has been slow to attract much research attention. However, more recently, there appears to be increased attention within health systems, including the mental health system, to exploring how service user participation in healthcare contexts can best be achieved. For example, in a study of people diagnosed with serious and persistent mental health problems, Tambuyzer \& Van Audenhove (2013) found that participatory activities improved self-rated outcomes for service users in the areas of empowerment and satisfaction. This resonates with the sentiment found in the post-psychiatry literature (for example, Bracken, 2012), which calls for a consciously interactive and dialogue-based relationship between psychiatrists and service users.

Charles, Gafni \& Whelan (1997) have attempted to parse the different elements of a shared treatment approach between service providers and service users. They identify three key stages of a collaborative service provider/service user relationship, 
namely, the exchange of information, the assessment (they term this the deliberation of the problem) and finally, the decision on how to address the agreed problem. This skills-based conceptualisation of participation is suggestive of a technical operation. Other writers view the act of participation as more complex and nuanced. For example, Street \& Millay (2001) offer an interactive vision of 'patient participation' which they describe as:

the extent to which patients produce verbal responses that significantly influence the content and structure of the interaction as well as the healthcare provider's beliefs and behaviours (Street \& Millay, 2001, p. 63)

Street \& Millay's (2001) definition thus depicts participation as an interactive or exchange-based process within which the views of service users on aspects of their health and healthcare are afforded importance by the service provider. However, this definition fails to specify if it anticipates service users as simply responding to, as opposed to creating or leading, these exchanges or what role they might play in deciding the content of such provider/user interactions. Similar to Charles, Gafni $\&$ Whelan (1997), Street \& Millay's (2001) vision of participation does not fully dislodge the physician (expert) and service user (non-expert) model of traditional mental health care.

In contrast, some writers propose that embracing the concept of participation requires rethinking the nature of the service provider/service user relationship. For example, Davies, Gray \& Webb (2014) distinguish between participation at an individual level and at a representative level in mental health care. At the level of the individual service user, they propose that participation entails, 'a collaborative or client-driven approach to decisions about the person's choice of service, choice of treatment and mode of treatment' (ibid, p, 119). In this definition, the authors emphasize a liberatory conceptualisation of participation, which underscores the autonomy of the service user to make, or at least be fully involved in, the decisions regarding their treatment. Furthermore, in this definition the service user is an active (as opposed to passive) agent in the processes related to their mental health care and, as such, Davies, Gray \& Webb (2014) construct participation as 'not just a static human right, but an active dynamic process' (p. 124).

Similar to Davies, Gray \& Webb (2014), Beresford \& Croft (1993; 2004) and Beresford (2007a) view participation as a step towards achieving restructured power relations between mental health service providers and service users. Craig (2003), writing in the context of children's participation, highlights the need to consider how best to sustain systems of participation, arguing that service user participation cannot be relegated to an optional element of service delivery, but instead it must be embedded as a solid feature of the various structures, processes and mechanisms through which service providers and service users interact (ibid, p. 49).

An additional problem for service users regarding their active participation in the mental health arena is what Beresford (2007b) describes as 'the concept of 
valid knowledge' and the extent to which service providers are willing to not only acknowledge but value knowledge derived from service user experience (see also Ardila-Gómez, 2014). In a socio-political analysis of power and social justice, Fraser (2005, pp. 6-7) highlights the 'power of recognition' (by which she means being heard, listened to and acknowledged) within social systems. The 'power of recognition' for mental health service users concerns not only being heard but also being accepted as bona fide actors and contributors in the decision-making processes that affect them regarding their mental health care. In the mental health services context, service users are not always recognised by service providers as 'valid knowledge' carriers. Similarly, Kennedy Chapin (1995) argues that for inclusive and empowering social policies to be enacted there needs to be a move away from a deficit-laden conceptualisation of people with mental health problems.

A transformative vision of service user participation raises challenges for mental health service systems where traditionally service users are viewed as deserving paternalistic protection and lacking in decision-making capacity. The inherent conundrum in a transformative participation model is how to reconcile the power of recognition with this 'vulnerable' characterisation of psychiatric patienthood. It is this conundrum which lies at the heart of the tensions surrounding participation and which renders difficult attempts to diffuse the concept of participation from policy into practice. The purpose of the study reported here was to give voice to mental health service users on their vision of a participatory model of mental health care in order to ensure that the service user voice is heard in the ongoing debate regarding the roll-out of participatory service initiatives.

\section{Methodology}

In support of Fraser's (2005) concept of the 'power of recognition', this study positioned the views of service users as central to the knowledge it aimed to produce. A narrative methodology, in the qualitative tradition, informed the research design. The narrative approach was chosen because of its capacity to bring the researcher into close proximity with the perceptions, meanings and viewpoints of the research participants. It was also selected because of its capacity to give voice to silent or silenced groups (Evans, 1993). In this light, a fundamental objective of the study was to avoid what Costa et al (2012) refer to as the 'sanitizing' of the stories and experiences of mental health service users and instead to both reveal and preserve the viewpoints of the participants as forged through their own experiences.

Reissman (1993, p. 17) contends that there is no singular definition of narrative research rather a spectrum of ways in which narratives and life stories can be used as research forms. From the range of available narrative methods, the Voice Centred Relational Method (VCRM) (Doucet \& Mauthner, 2008) was chosen because it provided a process through which the research participants could engage in open 
dialogue on the research topic and it facilitated the collection of service users' views on participation positioned within narratives of their lived experiences. Gilligan, Spencer, Weinberg \& Bertsch (2006, pp. 254-55) suggest that VCRM respects the inner world logic of the research subject and offers a route into their 'unique subjectivity' and 'meaning-making processes'. This method of data collection provided a means through which the researched and the researcher could engage in a process of 'thoughtful engagement' (Nicholson, 2009, p. 323) with the experiences of service user participation as the central focus.

Participant recruitment was conducted by the distribution to potential research participants of an Information Leaflet about the research project issued through gatekeepers based in mental health services and support organisations. The inclusion criteria required potential participants to have experienced long-term contact with mental health services. The Research Ethics Committee at the researcher's university granted permission for the study and approval was also granted by an ethics committee in one of the organisations which helped distribute the invitation to potential participants. In constructing the design of the study, advice was also provided by a national service user organisation.

In the research interviews, participants were asked to draw on their experiences of long-term engagement with mental health services to illustrate their views on participation as shaped by their personal experiences of service usage. A detailed analysis of nine interviews with service users was conducted. The interview data contained extensive and rich detail on the lived experiences of service users regarding their contacts with mental health services in general, and participation at the individual level of service usage in particular.

The data analysis was informed by Doucet \& Mauthner's (2008) 'Listening Guide'. In this approach the analysis of data is conducted through a series of stages supported by a process of repeat readings of transcripts and repeat listenings to the audiorecorded data. Despite limitations regarding sample size and generalisations, the study provided a rarely achieved insight into how participation is conceptualised and narrated by long-term mental health service users, a group often invisible and inaudible within the wider mental health research field.

\section{Findings}

The research interviews generated a large dataset rich in detail on the participants' views on service user participation. This article presents selective findings related to participation in the processes of help-seeking, diagnosis and treatment planning. As will be seen, some of the research participants provided examples where they experienced positive acts of participation but others recounted more pessimistic 
narratives of participation related to their personal experiences. In this article, all names and identifying details of study participants, family members or professionals have been pseudonymised.

\section{Participation in the process of help-seeking}

During their interviews, all the research participants discussed their efforts to seek help from services when their mental health deteriorated. For some participants, they themselves initiated contact with services, usually via their General Practitioner (GP). For others, contact with services arose from crisis situations or because people in their immediate social network, such as family members, sought help on their behalf. The analysis revealed examples of both positive and negative experiences of participation by service users related to occasions when they engaged in help-seeking in relation to their mental health concerns.

For example, having concealed strong suicidal ideation for some time, Oscar outlined being brought by family members to the Accident and Emergency Department of his local hospital, where he experienced the staff he met there as patient and supportive. Earlier that day, Oscar had attempted suicide and was still experiencing suicidal ideation when he was accompanied by family members to the hospital. He was admitted to hospital that day and thus began a period of inpatient care lasting almost 6 months, which despite the longevity of that hospital stay, Oscar regards as a life-saving experience for him. It was on the day of admission that Oscar first met the Consultant Psychiatrist who would oversee his diagnosis and treatment in the months that followed. From the beginning, Oscar experienced his interactions with this doctor as open and supportive:

Along came a man called Dr B. who ended up being my psychiatrist. And he actually saved my life. Within 2, 3 hours of that I was brought down to the X Department [psychiatric unit] of Z Hospital and I'd never been in anywhere like that in my life. (Oscar)

An important aspect of Oscar's ongoing journey through treatment and recovery, was his perception, forged through supportive conversations with Dr B and members of the wider mental health team, that his views on his mental health and related issues were valued:

He gave me time and he gave himself time to see the inner person and he didn't make assumptions. He, he let you free flow and talk and he'd take these notes. (Oscar)

Oscar was praiseworthy of the Consultant Psychiatrist and the broader mental health team in the hospital for their efforts to understand his mental distress and to 
help him recover his mental wellbeing. He explained his sense of belief in their work as flowing from the respect they displayed for his views and their acknowledgement of his efforts to deal with his mental health problems. This included their patience and belief in him even during periods of relapse, for example, after an occasion in which he concealed tablets and attempted to overdose. Oscar indicated that he enjoyed and continues to enjoy good relationships with most of the staff team assigned to his care and that he has ongoing confidence that help is available to him when he needs it.

Eric had a more nuanced history of participation in his help-seeking contacts with mental health services. He recalled that his life was going quite well when he first experienced auditory hallucinations and mood swings and in his own words he 'didn't know how to interact with them or deal with the voices I was hearing... I didn't have a clue about it'. In the research interview, Eric outlined that he has experienced symptom relapse on a regular basis over a period of twenty or more years. In his narrative, he reported periods of ill-health during those two decades when he has experienced recurring and distressing symptoms which he named as delusions but which he explains feel very real and terrifying when they are happening and at times they have a physically uncomfortable or painful dimension to them. Similar to Oscar, Eric emphasised the benefits he has gained from being in contact with a helpful team of mental health professionals, his Consultant Psychiatrist in particular. His view was that service users need understanding and acceptance from service providers and the opportunity to tease out what their symptoms mean and how they can be managed. Referring to his first time as an inpatient (he has lost count now on the number of hospital admissions he has experienced), Eric recounted the opportunity for participation through conversations with his doctor which were pivotal in helping him navigate that difficult period in his life:

Like the time when I was in hospital and he would be doing his rounds. I would really look forward to sitting down for 20 minutes maybe half an hour and having a chat and talking about some of my strange theories ... it was nice to have someone there that would listen (Eric)

Later in the interview, Eric reflected that the service providers he has encountered have been central to his ability to keep going despite ongoing experiences of problematic symptoms. When he spoke about his interactions with the mental health team members he consistently used the term 'we; suggesting that for him, contact with services has been a shared or participatory experience:

I do feel like my psychiatry team did help me along the way ... we were dealing with very hard issues... I do confide in my consultant ... they were there for me when I needed them at my darkest hour (Eric) 
In contrast to Oscar and Eric, other interviewees revealed less positive experiences of participation in the processes of help-seeking. For example, Amy, who at the time of interview was in her late twenties, revealed that she has been attending mental health services for approximately ten years for issues including self-harm, an eating disorder and depression. In her narrative, she offered many observations on the importance of being accepted and listened to by service providers and how this is central to the service user's ability to participate in the processes of help-seeking, diagnosis and treatment. Her narrative depicted Amy's position during her contact with service providers as external to the service system in that she did not view her contacts with services as participative, even though she would have valued such an approach. She also recounted her referral to services as an external event over which she had no control. Amy was in post primary education when her school referred her to a psychologist, but due to waiting lists in operation at the time, a year elapsed before she was first seen by the psychologist. This gap in time left Amy very much on her own trying to cope with her symptoms. When she finally accessed services, she felt her coping skills during the waiting period were not acknowledged and that decisions regarding her symptoms and needs were then made with little input on her part. She was particularly critical of being prescribed medication one week before a major examination, especially in light of the fact that she had been coping (with great difficulty) up to that point in time:

I didn't get to see the psychologist 'til the following year - it was a year waiting list... I got referred maybe 6 months after that to the psychiatrist I think the week before my Leaving Certificate and the psychiatrist thought it was a good idea to put me on medication (Amy)

In her narrative, the services Amy received were portrayed as part of a monolithic system of healthcare with which she has had no power of negotiation and is unable to access help except when her mental health deteriorates into a crisis:

You always had to be at rock bottom to speak to somebody em and that's obviously not the best time to speak to somebody when you are at rock bottom because you have nothing to say because everything is just too overwhelming (Amy)

The importance of a trusted relationship with a service provider is highlighted later in Amy's narrative. She has found it difficult to open up to service providers, partly because she has had some difficult encounters in her contacts with services and also partly because she finds some of her symptoms embarrassing to talk about:

I needed to talk to someone longer than 5 minutes. I needed, I needed somebody. I didn't trust the medication even though I took it I didn't trust it. I needed someone to help me understand why I was taking it and how important it was to take it correctly 
and I needed someone who wasn't freaked out by self-harm. I needed someone who didn't roll their eyes when I told them I cut ... if you want to speak to me you have to earn my trust and you haven't earned my trust by speaking to me for 5 minute (Amy)

Sofia's narrative depicts a labyrinthine route into accessing services. Her first episode of paranoid psychosis, occurring when she was in her twenties, was experienced by her as unexpected and sudden. She described how difficult it was to access appropriate support on the day when she first became acutely unwell. She acknowledged this occurred over twenty years ago, but later attempts to re-engage with mental health services have, in her view, confirmed for her that little has changed in how services can be accessed. Since her first hospitalisation, Sofia has had intermittent contact with mainstream mental health services. Although she has been involuntarily hospitalised on two occasions she has also had long periods of time in which she has not regularly attending mainstream mental health services. When she noticed a sharp decline in her mental health about two years before the research interview, Sofia tried to re-establish contact with mental health services with the assistance of her GP in order to try to avoid another mental health crisis or involuntary admission. There was a delay in getting an appointment, and in the interview this underpinned her criticism regarding how services respond (or not) to the requests for help from service users:

Because for me to re-engage, having been through the services over the last 20 years, for me to re-engage I had to go back through the hoops of being referred by my GP to one place and that didn't work, then being referred to the other place and then wait and then follow up myself to try and get appointments (Sofia)

Like Amy, Sofia's narrative positioned her as powerless in her efforts to get help when she felt she needed it. When her health declined she attempted to seek out appropriate help but this was thwarted by an unresponsive, inaccessible service structure which obstructed her efforts to access the help she believed she needed in a timely fashion. Her narrative contrasted her hope-inspired voluntary impetus to re-engage with services with the dissatisfaction she felt when the services she contacted did not respond efficiently to her request for help.

\section{Participation in the process of diagnosis}

This section contrasts the narratives of two participants, Arthur and Kyle. These are exemplars and other narratives collected in the study echoed similar viewpoints.

When his symptoms first emerged, Arthur described feeling frightened, ashamed and embarrassed by them. He summoned the courage, he recalled, to confide in his psychiatrist about various issues which he was experiencing related to his 
symptoms (he does not reveal these issues during the interview). He stated that his psychiatrist encouraged him to disclose more detail about his symptoms in a letter to the psychiatrist. Arthur complied with this suggestion and in his own words 'spilled out my guts'; however, the psychiatrist did not provide a response or discuss the letter with Arthur. This lack of response left Arthur with feelings of confusion about how his views were being incorporated into his diagnosis, how they were being interpreted and who had access to the information he provided in written form. In his interview, Arthur described feeling betrayed at the time and how he continued to carry those feelings of betrayal despite an interval of thirty years since he wrote the letter to the psychiatrist. He disclosed that following this event he never fully regained the motivation to participate fully with services:

I went through a lot of trauma in my late, early, mid-twenties em eventually I sought help from the psychiatric professions. And I didn't get the help, they never seriously entertained it as being a contributory cause to my unwellness and em this particular psychiatrist for once I thought was showing an interest in me as a person rather than me as a bag of symptoms and... I said I finally have a chance to eh to maybe deal with issues that I want to deal with in a serious way so I wrote a very honest account of the problems I had encountered... I gave it to him and I never heard another word from him about it and I felt utterly literally abused - I had spilled out my guts in an effort to seek help and it was, it was totally ignored (Arthur)

Kyle explained that his symptoms of mental illness started in his teenage years and since then he has had a number of hospital admissions and has experienced contact with a wide range of mental health service providers in both the child and adolescent mental health services and the adult mental health service. Derived from his experience of multiple hospital admissions but also from contact with private psychotherapy services, Kyle suggested that service user participation is dependent on the effort by service providers to reassure the service user that the service user's explanation of their symptoms will be heeded and will be incorporated into the collaborative effort to find solutions. His views have been shaped by a mixture of both positive and negative experiences with services. For example, he recounted the night of an emergency admission to hospital after he had attempted suicide when he felt further traumatised by the lack of concern expressed by the staff he met:

I was very vulnerable at that time cos I had just tried to you know kill myself and I was really raw you know and like I suffer anxiety and I get very shaky with that ...so I'm sure visually I looked like you know I wasn't speaking sense... but the problem was that there was no, I felt like they never took the time to participate me enough in my own care to be able to hear that actually this fella has had a really tough time. Like they take your history when you go in for your admission but I felt like they never really took that and continued that as part of your care (Kyle) 
Kyle contrasted his interactions with members of the hospital mental health team in the example above with the inclusive and collaborative experience of his first appointment with a psychotherapist he privately sourced when he felt he could no longer continue to comply with the medical treatment plan that was offered to him in the hospital. In their first meeting, Kyle felt his viewpoints on his mental ill-health were valued by the psychotherapist:

I felt it was the first time ever I felt somebody who was meant to be there to care for me recognised what it was that was actually going on for me do you know and really listened to me .. And I remember her words were: 'you know I don't have the solution for this but between the two of us we will try to figure this out together'. And ah it just my whole body and everything in me just relaxed and I just said: 'finally, yeah, someone is actually listening to me' (Kyle)

Kyle reported that his mental health team were unhappy that he had started to attend a private psychotherapist and he was forced to choose between one service or the other. He opted to continue with the psychotherapist and since then has graduated from university, is working full-time and is medication free for a number of years.

\section{Participation in the process of treatment decisions}

The data analysis illuminated the importance for service users of being involved in treatment decisions. For example, as outlined earlier, Eric was generally positive about his interactions with mental health services, believing he might not be alive now without the help he has received. Nonetheless, an ambiguity arose in Eric's narrative as he displayed scepticism regarding the purely medical explanation of his symptoms put forward by his treatment team and he indicated that he would welcome more opportunities for symptom interpretation and management through alternative paradigms. During his interview, Eric fluctuated between identifying his symptoms as delusions and 'part of my illness' to disclosing that he was not fully satisfied with a purely medical explanation. He regarded the medical model as limited in helping him tackle the persistent and disturbing hallucinations and delusions he has experienced for many years, many of which include religious or somatic content. Eric has found it very difficult to engage his doctors in any discussion on alternative approaches to managing his symptoms and this has left him feeling very alone when his symptoms become difficult for him to cope with:

I spoke about this, I spoke to the psychiatrists but I don't think they wanted to deal with like you know I just think they found they had no answers for it and... so I just had to buck up myself and look after myself (Eric)

Eric's ambivalence towards the individual pathology model of mental illness has 
isolated him from the dominant paradigm on which his treatment relies and this dissonance between his perspective and those of the service providers, in his view, has obstructed both parties' ability to fully engage in shared treatment decisions. Essentially, Eric has found that there has been no opportunity to consider alternative non-pharmaceutical treatment options, except for when he has occasionally taken part in relaxation groups as a supplement to rather than a replacement for his medication. Nonetheless, Eric spoke warmly of the service providers he has encountered and he perceived his relationship with them as generally supportive, suggesting that he has been able to participate in other aspects of his treatment plan despite this lack of agreement on the management of his psychotic symptoms.

Amy's narrative revealed a different form of obstruction to shared treatment decision-making. Similar to points made by Max in his interview where he emphasised his fatigue with constantly being asked to re-tell his illness history to new staff, Amy criticised the organisational arrangements in public mental health services which rotate doctors on a frequent (6-monthly) basis. For her, this rotation has left her without contact with a key service provider who knows her story and understands her needs. It has also caused a lack of consistency in her treatment plan:

In those ten years, every single time it has been a different psychiatrist, every single time and so there was never anything to measure me against em I was always - I have a huge file as you can imagine - so they're scurrying through the file and spend most of the time going through the file em trying to figure out em what's going on and then it's always the option is increase the medication always increase the medication and you really feel that if you don't take the medication that you are not being compliant and that you are a troublemaker or that if you question them you are a troublemaker (Amy)

For Amy the bottom line regarding participation was that service users need to feel they are being taken seriously by service providers and that their views on their situation are being taken into account:

I just want to be treated with respect em treated with respect and I think that, I think you need to be, I think that the stuff that you are going through really needs to be valued is the wrong word but yeah listened to and you need to feel that you are supported (Amy)

Sofia has had intermittent contact with mental health services over the period of twenty years since her first involuntary hospitalisation. Separate from any treatment she has received from mainstream mental health services, she has also engaged with the Wellness Recovery Action Program (WRAP) (Copeland, 2005), which is a programme designed to assist people to manage their own mental health. For Sofia, this programme has given her a sense of control over her efforts to maintain her mental health: 
I just loved the whole you know taking control and being, being em responsible for your own wellbeing and being responsible you know choosing your own path and what works for you and what doesn't work... I just think it is really empowering (Sofia)

However, on re-engagement two years ago with mainstream mental health services, Sofia encountered a limited availability within the mainstream mental health service of recovery-based, non-medical support services. She also noted that when such services, for example counselling, are made available that there is a lack of flexibility in how appointments are organised, with little regard shown for the other commitments in her life:

But even while it has been my choice to participate in the services again I just feel that the services are not there for people...I was willing to participate in mental health services to maintain my wellness and for me I think counselling has worked for me absolutely that's as effective as medication...There is no accommodation for me that I have children so for me now even to go to the clinic ... I have to find childcare ... you know the services are 9 to 5 Monday to Friday (Sofia)

Kyle's narrative of in-patient care ended in complete conflict between him and the hospital mental health team. He described himself as initially being quite deferential to the expertise of the mental health service providers during the early years of his contact with mental health services. He reported that he also found the medication he was prescribed helpful to a certain degree. However, the persistence of his symptoms, culminating in a second suicide attempt when he was in his midtwenties led him to question 'everything' about his diagnosis and the treatment plan that had been prescribed for him (which was purely medicine-based). He recounted trying to engage in an interactional process of participation with the hospital mental health team during his third admission to hospital but found his efforts to initiate discussions regarding his treatment plan were resisted and shut down:

I kind of felt this is not really fitting with me and any time I tried to bring it up it was, you know, 'oh, we'll change your meds' or you know, 'it's just not working for you'. And I was kind of like, 'this is not what I am trying to say to you, what I am trying to say to you is that what you are saying is wrong with me is not really fitting exactly you know with what is going on for me'. And I guess at that time when I was 25 at that stage I had researched a lot myself around stuff and kind of began to get interested in what they were saying to me and the different treatment that were available and I had never been offered any other treatments besides medication' (Kyle)

Kyle vividly recalled the interaction in which his view of his treatment plan collided with that of the psychiatrist: 
And I remember going in for one of those review meetings with the consultant psychiatrist. And I remember saying to him you know, 'listen I have been very emotionally damaged and I think what is wrong with me is that I don't know how to regulate myself properly and I think that's why I'm getting overwhelmed'... and he was just kind of like, 'you don't know what you are talking about, we are the ones that are ... looking after your treatment and stuff and you know what it sounds like to me is that you are about to have another manic episode' (Kyle)

At this point in time, Kyle viewed the dismissal of his questions and his viewpoints as the opposite of participation. For him, this encounter with his psychiatrist lacked what he referred to as 'the human piece' which he explained to mean the service provider being able to accommodate the service user's opinions and to accept that they might not fully understand all the factors relevant to the onset or endurance of the service user's symptoms.

In contrast to Kyle's decision to abruptly end his contact with mainstream services and seek out alternative help, Ultan has maintained a more silent objection to how his treatment plan is usually decided. Although still involved with mental health services and fully compliant with his treatment plan, Ultan's narrative revealed the potential for compliance to be confused with agreement or participation. For Ultan, experience has led him to conclude that the inherent power imbalance between service users and service providers cannot be recalibrated. For Ultan, there is no point in sharing information about his symptoms or his wider, personal needs because he views will not be valued:

It's a waste of time saying it, they're gonna make up their own minds. What you, you know, whatever I say, they make up their own minds... Even recently, where I was, I would have loved to go in and say to the doctor, 'look doctor I'm not well really and I'm up and down'. I would have loved to say that on a couple of occasions throughout my life, I would have loved it but I never did, I just didn't... They make up their own minds (Ultan)

When prompted to indicate how the service providers he has met could have better identified his treatment needs if he is not expressing his views to them, Ultan was very clear in his response that his views could contribute useful information into the treatment scenario. However, based on his experience over many years, Ultan is convinced that the doctor's assessment (derived from standardised questioning) would be regarded as superior to any view that he, Ultan, could provide about his own situation or what might be of assistance to him. As a consequence, Ultan no longer tries to influence the treatment plan and confines himself to answering the doctor's questions - 'their questions': 
The questions, their questions .... questions, questions, questions, questions, questions... The way I look at it they're, they're gonna make their own minds up (Ultan)

Ultan's experiences have led him to conclude that the standardised questioning routine, that he regularly encounters in his appointments with the doctor, lies at the centre of the decisions that are made (outside his control) by the doctors concerning his treatment. For Ultan, this is not what he considers optimum participation by him. When asked to provide his ideal version of optimum participation, Ultan described it as follows:

Well now if I was in charge and someone came to see me, first of all I would, I would listen to what they had to say and I would listen and not say anything and I would work with them, I'd be more, let's say for want of a better word, 'softer' than an average doctor, and I've been there, I've felt that you know. I've been depressed, I've been in hospital, I know what it's like, so if someone put me in charge and let's say there was a patient out there... I would listen to them and I would have an in-depth understanding of the situation cos I've been there myself. The main thing would be sit and listen to them and see what problems, see what they want (Ultan).

\section{Discussion}

The study featured here provided an opportunity for service users to voice their experiences of participation in their contacts with mainstream mental health services in the Irish context. This article has focused on reporting selective findings from the study related to service user participation in the context of help-seeking, diagnosis and treatment decision-making.

The study reveals the importance for service users, if their participation is to be optimised, of feeling heeded by service providers, treated with respect and understood in their wider context. For example, both Oscar and Eric reported, as positive examples of participation, encounters with mental health service providers who were willing to engage in dialogue-based exchanges similar to that proposed by Bracken (2012). It was clear from their narratives that both Oscar and Eric experienced these supportive conversations as participation pathways through which their views were actively sought and taken into account. This also suggests that in such instances, Oscar and Eric were regarded as valid knowledge holders by the service providers they encountered (Beresford, 2007b). In contrast, other interviewees recounted experiences in which they could not access supportive help easily.

The narratives from a range of participants revealed how symptoms can be experienced as frightening, disabling and confusing as well as difficult or 
embarrassing to talk about to others. The data displayed examples of interactions between service providers and service users which either assisted or inhibited symptom exploration. The relational dimension of participation was discernible in some of the narratives, Amy's in particular, where she emphasised how being listened to and respected were necessary if she was to feel she could trust the service providers she met. The narrative accounts illustrated that obstacles such as constantly changing staff or routinised assessment procedures can shut down rather than encourage service user engagement and participation in the processes of help-seeking, diagnosis and treatment.

Eric's (also Kyle and Arthur) narrative revealed that being involved in the process of diagnosis is important for service users, not simply because it is the gateway to services and medication, but also because they hope it will explain why their mental health problems and symptoms have occurred in the first place. A number of the participants highlighted the difficulties for service users in participating in the process of diagnosis when that process was confined to interpretation of mental distress within the medical paradigm. Many of the narratives traced the frustrations felt by service users when explanations for their conditions were interpreted solely within an individual pathology paradigm. Some study participants associated the onset or persistence of their mental illness symptoms with non-medical factors. These participants also recounted how the service providers they encountered often struggled to incorporate such information into mental health assessments and treatment decisions, thereby falling short of the collaborative, client-driven model of participation outlined by Davis, Gray \& Webb (2014).

The dismissal or failure to accommodate the service users' viewpoints or 'truth' in the processes of diagnosis and treatment led, in some cases, to fractured relationships between the service users and the service system with which they were trying to engage. This manifested itself in different ways. For Ultan, the lack of attention to his viewpoints, has silenced his contributions in contacts with the mental health service providers he meets and he simply conceals his truth and concedes decisionmaking power to the doctor. For Kyle, he believed his recovery was compromised by the disparity between his 'truth' and the power-to-decide on diagnosis and treatment held by service providers. He found alternative forms of support outside the mainstream mental health services where he believed his participation was valued and regarded as an asset in his recovery. His account of contact with the private psychotherapist comes closest, in all the narratives, to Croft \& Beresford's (1993; 2004) vision of a power-sharing, client-led treatment process. Sophia managed to arrange within mainstream services the counselling support she believed she needed but found that others held the power to determine crucial decisions regarding access to that support such as when it was available to her and how many sessions she could attend. Like Amy and Max, Sophia expressed disillusionment regarding the low level of influence her participation ultimately wielded in treatment decisions.

The assumption underpinning the promotion of participation in Irish mental 
health policy (DoH, 2006, 2020) is that it will render the mental health system more human-rights compliant in its role of delivering mental health services to the Irish population. However, the narratives collected in this study illuminated the difficulties involved in rolling out the promise of participation within a system where service providers, in their expert role, are charged with the responsibility of diagnosing mental illness and managing any risks which may arise. The tentative findings from this small, exploratory study suggest that more knowledge is needed to better understand these dynamics. In particular, more research is needed to reveal the dynamics of power which encircle the roll out of participatory models of service delivery and how the responsibilities placed on the shoulders of mental health service providers can be reconciled with the form of optimum participation envisioned in this study by service users.

\section{Concluding Comments}

The narratives collected for the purposes of the present study contain extensive and rich detail on the lived experiences of a sample group of mental health service users. As the findings reveal, service users have much to say on the issue of service user participation in the context of Irish mental health service delivery. The present study offers a rarely achieved insight into how participation is conceptualised and experienced by mental health service users, a group often invisible and inaudible within the wider research field. The interviews produced deep level insights into the experiences of participation and service usage across the sample population and the analysis reveals information on many aspects of participation and how it is perceived by the study participants. The present study points to challenges of enacting a participatory agenda in the context of mental health services and there are many suggestions from the interviewees on how that could be better achieved within the current context.

The present study also illuminates service user views on optimal participation and the positive potential of participatory-based models of service delivery in the mental health context. However, the findings spotlight factors which inhibit service user participation, as articulated by service users themselves. When service users are acknowledged as valid knowledge carriers (Beresford, 2007b) by the service providers they encounter, the study findings reveal that participation supports respectful relationships, recognition of personhood and a context of co-enquiry. The findings also indicate that open and respectful communication is regarded by service users as central to optimum participation experiences.

However, the findings reveal the chilling effect on participation of power imbalances between providers and users. This arises where service user views on their diagnosis or preferred treatment options are dismissed or ignored because they 
do not conform to the diagnostic or treatment paradigm of the service provider. The findings suggest that participation cannot be considered in isolation and recognition must be afforded to factors such as paradigm domination and power inequalities between providers and users.

It is clear from the findings of this preliminary study that more knowledge is needed to better understand the dynamics of service user participation in the context of mental health care. In particular, more research is needed to reveal the dynamics of power which encircle the roll out of participatory models of service delivery and which, if left unaddressed, will potentially stifle its rights-promoting intent.

\section{References}

Ardila-Gómez, S. (2014) Users' Perspecives on Evaluation of mental health services: experience from a discharge program in Argentina. International Journal of Mental Health, 43, 2, 70-80

Beresford, P. (2007a) User involvement, research and health inequalities: Developing new directions. Health and Social Care in the Community, 15, 4, 306-312

Beresford, P. (2007b) The role of service user knowledge in generating knowledge-based health and social care: from conflict to contribution. Evidence \& Policy, 3, 3, 329-341

Beresford, P. (2012) The theory and philosophy behind user involvement. In P. Beresford \& S. Carr (Eds.) Social Care, Service Users and User Involvement. London: Jessica Kingsley Beresford, P. \& Croft, S. (1993) Citizen Involvement: A practical guide for change. Hampshire: Macmillan Press

Beresford, P. \& Croft, S. (2004) Service users and practitioners reunited: The key component for social work reform. British Journal of Social Work, 34, 1, 53-68

Bracken, P. (2012) Psychiatric power: A personal view. Irish Journal of Psychological Medicine, 29, 1, 55-58

Charles, C., Gafni, A. \&Whelan, T. (1997) Shared decision-making in the medical encounter: What does it mean? (or it takes at least two to tango). Social Science and Medicine, 44, 681-692

Copeland, M.E. (2005) Wellness recovery action plan: A system for monitoring, reducing and eliminating uncomfortable or dangerous physical symptoms and distressing emotional feelings or experience. Liverpool: Sefton Recovery Group

Costa, L., Voronka, J., Landry, D., Reid, J., McFarlane, B., Reville, D. \& Church, K. (2012) Recovering our stories: A small act of resistance. Studies in Social Justice, 6, 1, 85-101

Craig, G. (2003) Children's participation through community development: Assessing the lessons from international experience. in C. Hallett \& A. Prout (Eds.) Hearing the Voices of Children: Social Policy for a New Century. London: Routledge Farmar

Croft, S. \& Beresford, P. (1992) The politics of participation. Critical Social Policy, 12, 35, 20-44

Davies, K., Gray, M. \& Webb, S.A. (2014) Putting the parity into service-user participation: 
An integrated model of social justice. International Journal of Social Welfare, 23, 119-127 Department of Health (2006) A Vision for Change. Report of the Expert Group on Mental Health Policy. Dublin, Ireland: Dept of Health. Accessed on 20 December 2019 at: https://www. hse.ie/eng/services/publications/mentalhealth/mental-health---a-vision-for-change.pdf

Department of Health (2020) Sharing the Vision: A mental health policy for everyone. Dublin, Ireland: Department of Health

Doucet, A. \& Mauthner, N.S. (2008) What can be known and how? Narrated subjects and the Listening Guide. Qualitative Research, 8, 3, 399-409

Evans, M. (1993) Reading lives: How The personal might be social. Sociology, 27, 1, 5-13

Fraser, N. (2005) Reforming justice in a globalising world. New Left Review, 36, 69-88

Gilligan, C., Spencer, R., Weinberg, M.K. \& Bertsch, T. (2009) On the Listening Guide: A voice-centred relational method. in S. Nagy Hesse-Biber \& P. Leavy (Eds.) Emergent Methods in Social Research. London: Sage

Kennedy Chapin, R. (1995) Social Policy Development: The Strengths Perspective. Social Work, 40, 4, 506-514

Kirwan, G. (2017) Mental Health Service Users' Narratives of Participation: Consensus, dissenus and paradox. Unpublished PhD Thesis, Trinity College Dublin, Ireland

Nicholson, H. (2009) Remembering conversations: reflections on research. The Journal of Applied Theatre and Performance, 14, 3, 323-328

Reissman, C.K. (1993) Narrative Analysis. London: Sage

Stiggelbout, A.M., Pieterse, A.H. \& De Haes, J.C.J.M. (2015) Shared decision making: Concepts, evidence, and practice. Patient Education and Counselling, 98, 1172-1179

Street (Jr), R.L. \& Millay, B. (2001) Analyzing patient participation in medical encounters. Health Communication, 13, 1, 61-73

Tambuyzer, E. \& Van Audenhove, C. (2013) Is perceived patient involvement in mental health care associated with satisfaction and empowerment? Health Expectations, 18, 516-526

Veatch, R.M. (1972) Models for ethical medicine in a revolutionary age. What physicianpatient roles foster the most ethical relationship? The Hastings Centre Report, 2, 3, 5-7

World Health Organisation (2013) Mental Health Action Plan 2013-2020. World Health Organisation. Accessed on 18 December 2019 at: https://www.who.int/mental_health/ action_plan_2013/en/

World Health Organisation (2019) Mental Disorders. WHO Fact Sheet. Accessed on 20 December 2019 at https://www.who.int/news-room/fact-sheets/detail/mental-disorders

World Health Organisation's Regional Office for Europe (2019) Mental Health: fact sheet. Accessed on 20 December 2019 at file://C:/Users/kirwangm/Documents/ SocWkSocScReview/Part2/Kirwan/MNH_FactSheet_ENG.pdf 